\title{
A V Phenomenon
}

\section{Partha Haradhan Chowdhury ${ }^{*}$, Brinda Haren Shah ${ }^{2}$ and Nripesh}

\section{Tiwari $^{3}$}

${ }^{1}$ M.Optom, Associate Professor, Principal, Department of Optometry, Shree Satchandi

\section{Short Communication}

Volume 3 Special Issue 1

Received Date: September 10, 2018

Published Date: October 04, 2018

Jankalyan Samiti Netra Prasikshan Sansthan, Pauri, Affiliated to Uttarakhand State Medical Faculty, Dehradun, India ${ }^{2}$ M.Optom, Guest Lecturer, Department of Optometry, Shree Satchandi Jankalyan Samiti Netra Prasikshan Sansthan, Pauri, Affiliated to Uttarakhand State Medical Faculty, Dehradun, India

${ }^{3}$ D.Optom, General Secretary and Chief Optometrist, Department of Optometry, Shree Satchandi Jankalyan Samiti Netra Prasikshan Sansthan, Pauri, Affiliated to Uttarakhand State Medical Faculty, Dehradun, India

*Corresponding author: Partha Haradhan Chowdhury, M. Optom, Associate Professor, Principal, Department of Optometry, Shree Satchandi Jankalyan Samiti Netra Prasikshan Sansthan, Pauri, Affiliated to Uttarakhand State Medical Faculty, Dehradun, India, Email: optometrypublish@gmail.com

\section{Abstract}

This paper describes about A pattern, $\mathrm{V}$ pattern, $\mathrm{X}$ pattern and its treatment.

Keywords: A pattern; V pattern; X pattern

\section{Introduction}

The main reason of A-V pattern is "OM over action/ OM paresis and or Brown syndrome. During horizontal movement, there will be significant difference between up gaze and down gaze.

"A pattern" is considered when the deviation between up gaze and down gaze is at least $10 \mathrm{PD}$. It is considered when divergence is more at down gaze as compared to up gaze. It's subtype is: Lamda pattern. In case of Lamda pattern, during horizontal movement eye is divergent more at down gaze but no significant deviation is seen in up gaze.

A pattern is classified as:

- "XT" - A pattern

- "ET" - A pattern eg like $V$ pattern
"V pattern" is considered when during horizontal movement eye is diverged more at up gaze compared to down gaze. The difference between up gaze and down gaze will be at least 15 PD.

Sub types of $\mathrm{V}$ pattern are $\mathrm{Y}$ pattern and Arrow pattern. $\mathrm{V}$ pattern is classified as:

- "XT" - V pattern

- "ET" - V pattern

$\mathrm{XT}-\mathrm{V}$ pattern is considered when at up gaze $=\mathrm{XT} 30 \mathrm{PD}$, Primary $=$ XT 20 PD and at Down gaze - XT 10 PD

ET $-V$ pattern is considered when at up gaze $=$ ET $10 \mathrm{PD}$, Primary = ET 20 PD and at Down gaze - ET 30 PD

"X pattern" is considered when during horizontal movement eye will diverge at down gaze and at up gaze also. Usually, it is idiopathic condition and there may be a chance of long standing presence of large angle of Exotropia and may be chance of tight contracted LR muscle [1-3]. 


\section{Open Access Journal of Ophthalmology}

\section{Treatment of and V Pattern}

With minimal amount of $\mathrm{A}$ and $\mathrm{V}$ pattern, it can be treated by offsetting or transposing the Horizontal Rectus muscle. The meaning of Transposing or offsetting is Medial Rectus can be displaced towards up and towards down. It is always remembered that, Medial Rectus muscle insertion is displaced towards the apex of the deviation. So, in case of A pattern, Medial Rectus muscle insertion will be displaced towards apex position. i.e. up gaze. "Lateral Rectus muscle insertion is displaced towards widening part. i.e. During A pattern, Lateral muscle insertion is displaced towards down gaze. Most of the time, muscle recession is also needed with offsetting $[4,5]$.

\section{References}

1 Kenneth W Wright, Peter H Spiegel (2003) Pediatric Ophthalmology and Strabis-mus. 2nd (Edn.).

2 Kenneth W Wright, Peter H Spiegel, Lisa Thompson (2006) Handbook of Pediatric Strabismus and Amblyopia.

3 Kenneth W Wright (2007) Color Atlas of Strabismus Surgery: Strategies and Techniques.

4 Theodore Grosvenor, Theodore P (2007) Primary Care Optometry. 5th (Edn.).

5 Mitchell Scheiman, Bruce Wick (2008) Clinical Management of Binocular Vision. 3rd (Edn.). 